\title{
Role of granulysin in immunity to leprosy
}

\author{
M. T. OCHOA $^{1}$, S. THOMA-USZYNSKI ${ }^{1}$, \\ P. A. SIELING ${ }^{1}, \mathrm{~S} . \mathrm{SABET}^{1}, \mathrm{~S} . \mathrm{CHO}^{1}$,
} A. M. KRENSKY $Y^{4}$ A. BURDICK ${ }^{6}$, T. H. REA \& R. L. MODLIN ${ }^{1,2,3}$

${ }^{1}$ Division of Dermatology, ${ }^{2}$ Department of Microbiology and Immunology, and ${ }^{3}$ Molecular Biology Institute, University of California at Los Angeles School of Medicine, Los Angeles; ${ }^{4}$ Division of Immunology and Transplantation Biology, Department of Pediatrics, Stanford University, Stanford; ${ }^{5}$ Section of Dermatology, University of Southern California School of Medicine, Los Angeles, California; and ${ }^{6}$ Department of Dermatology and Cutaneous Surgery, University of Miami, Miami, Florida, USA

One component of human T-cell cytotoxic granules, granulysin, exhibits a broad spectrum of activity against microbial pathogens. We investigated the role of granulysin in human infectious diseases, employing leprosy as a model. Expression of granulysin was detected in cutaneous leprosy lesions six times more frequently among patients with localized than among those with disseminated disease. Granulysin co-localized in CD4+ T cells within leprosy lesions as well as in CD4+ T-cell clones derived from lesions. These CD4+ T cells lysed targets by means of the granule exocytosis pathway, and reduced the viability of both Mycobacterium tuberculosis and M. leprae in infected targets. These data indicate a direct effector function of CD4+ $\mathrm{T}$ cells that is mediated through their ability to secrete the antimicrobial protein, granulysin, at the site of the infection.

We also determined the distribution and frequency of granulysin in reactional states in leprosy. We found that expression of granulysin was greater among patients with reversal reactions than among those with erythema nodosum leprosum, and was least frequent among lepromatous patients who were not in reaction. These results suggested that granulysin can also contribute to bacterial killing during reactional states or lead to the tissue-injury typical of these reactions.

\section{DISCUSSION}

Dr Colston: How is production of granulysin by $\mathrm{T}$ cells regulated? Is it mediated by cytokines or by antigen-recognition?

Dr Modlin: After stimulation of the T-cell receptor, granulysin production is up-regulated after a period of $72 \mathrm{~h}$. It then remains, and is released by the next antigen stimulation.

Dr Dockrell: I'd like to hear more about the anti-mycobacterial effects of granulysin.

Dr Modlin: Granulysin killed extracellular as well as intracellular M. tuberculosis. 
Dr Ottenhoff: Do you speculate that CD8+ cells are not activated in leprosy lesions?

Dr Modlin: Either they are not activated, or they release their granulysin all at once. It may be that CD8+ cells are primarily cytolytic, and lyse the infected cells, whereas the CD4+ cells secrete granulysin, which can then enter the infected cells and kill the organisms.

Dr Krahenbuhl: The T cells also secrete very powerful cytokines, such as IFN $\gamma$, which attract macrophages, which have other means of killing organisms. Merely lysing the hostcell followed by the arrival of fresh macrophages in the lesion would also have powerful antimicrobial effects.

Dr Modlin: I agree. Clearly, there are multiple mechanisms of bacterial killing; macrophages represent an important mechanism, but $\mathrm{T}$ cells can also contribute by a direct antimicrobial effector pathway. 